\title{
Carlos Baliño, pioneiro do marxismo na América Latina
}

\section{Luiz Bernardo Pericás 1}

Resumo: este artigo discute a vida e pensamento político de Carlos Baliño, pioneiro do marxismo na América Latina. Seu ativismo nos Estados Unidos e em Cuba, sua relação com José Martí, seu vínculo com Julio Antonio Mella, seu envolvimento em diferentes organizações políticas e a fundação do Partido Comunista Cubano são elementos abordados aqui.

Palavras-chave: Carlos Baliño; Cuba; marxismo.

\section{Carlos Baliño, pioneer of Marxism in Latin America}

\begin{abstract}
This article discusses the life and political thought of Carlos Baliño, a pioneer of Marxism in Latin America. His activism in the United States and Cuba, his relationship with José Martí, his ties with Julio Antonio Mella, his involvement in different political organizations and the foundation of the Cuban Communist Party are all elements discussed here.
\end{abstract}

Keywords: Carlos Baliño; Cuba; Marxism.

Artigo recebido em: 19/01/2016

Artigo aprovado para publicação em: 15/05/2016

“O primeiro marxista latino-americano". Esta afirmação polêmica de Carmen Gómez García sobre Carlos Baliño se contrapõe à visão mais tradicional propugnada por intelectuais como Francisco Posada e Antonio Melis, que defendiam que o jornalista peruano José Carlos Mariátegui ocupava aquele posto (GÓMEZ GARCIA, 1985, p. 206). Acompanhando esta posição, Michael Löwy sequer chegou a incluir Baliño em sua conhecida coletânea $O$ marxismo na América Latina:

\footnotetext{
${ }^{1}$ Professor de História Contemporânea da USP, autor de Che Guevara y el debate económico en Cuba (Fondo Editorial Casa de las Américas, 2014) e Caio Prado Júnior: uma biografia política (Boitempo, 2016), entre outros.
}

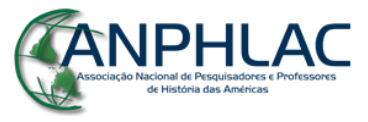

Revista Eletrônica da ANPHLAC, ISSN 1679-1061, №. 20, p. 126-140, Jan/Jun., 2016.

http://revista.anphlac.org.br 
uma antologia de 1909 aos dias atuais ${ }^{2}$ ou a mencioná-lo em seu prefácio. O mesmo pode ser dito de Luis E. Aguilar, no livro Marxism in Latin America ${ }^{3}$, uma compilação clássica sobre o tema publicada em 1968 pela Alfred A. Knopf. Nenhum artigo dele foi selecionado para fazer parte daquele volume. Até o dicionário biográfico América Latina en la Internacional Comunista, 19191943, preparado por Lazar Jeifets, Víctor Jeifets e Peter Huber ${ }^{4}$, deixa Baliño de fora de suas páginas, não constando sequer um verbete sobre o eminente socialista, ainda que ele tenha sido um dos principais fundadores do Partido Comunista Cubano em 1925. Por isso, as palavras de Blas Roca, escritas em 1941, infelizmente parecem manter sua atualidade: "Carlos Baliño não é mencionado nos textos de história nem nas obras dos literatos oficiais" (ROCA, Prólogo de Blas Roca al folleto Verdades del Socialismo, publicado originalmente in Verdades del Socialismo, Havana, Ediciones Sociales, 1941, e reproduzido in Instituto de Historia del Movimiento Comunista y de la Revolución Socialista de Cuba (org.), 1976, p. 95). Inclusive “entre os trabalhadores revolucionários incorporados à luta por um mundo melhor, Baliño é pouco conhecido" (IBID, p. 95).

Por outro lado, o cubano seria discutido, paradoxalmente, na Historia de la filosofía, um manual soviético preparado por um grupo de pesquisadores liderado por Mikhail Aleksandrovich Dynnik, junto a nomes como Juan Bautista Alberdi, Esteban Echeverría, Juan B. Justo, Domingo Faustino Sarmiento, Félix Varela, José Martí e até mesmo Vittorio Codovilla! (KOHAN, 2013. P. 180, 181) E também pelo historiador Sheldon B. Liss, que dedicará algumas páginas ao ativista havanês em seu Marxism in Latin America (LISS, 1984, p. 240-246).

É claro que em Cuba a obra do líder sindical seria divulgada depois da revolução. Biografias como aquelas escritas por Carmen Gómez García ${ }^{5}$ e Maria Serra, ${ }^{6}$ ou os volumes produzidos pelo

\footnotetext{
${ }^{2}$ Cf. Michael Löwy (org.). O marxismo na América Latina: uma antologia de 1909 aos dias atuais. São Paulo: Editora Fundação Perseu Abramo, 2012.

${ }^{3}$ Cf. Luis E. Aguilar (org.). Marxism in Latin America. Nova Iorque: Alfred A. Knopf, 1968.

${ }^{4}$ Cf. Lazar Jeifets; Víctor Jeifets; Peter Huber (orgs.). América Latina en la Internacional Comunista, 1919-1943. Santiago do Chile: Ariadna Ediciones, 2015.

${ }^{5}$ Cf. Carmen Gómez García. Carlos Baliño, primer pensador marxista cubano. Havana: Editorial de Ciencias Sociales, 1985.

${ }^{6}$ Cf. Mariana Serra. Carlos Baliño. Havana: Editorial Gente Nueva, 1985.
}

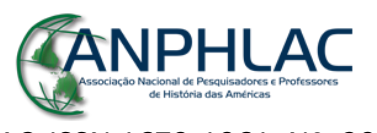

Revista Eletrônica da ANPHLAC, ISSN 1679-1061, №. 20, p. 126-140, Jan/Jun., 2016.

http://revista.anphlac.org.br 
Instituto de Historia del Movimiento Comunista y la Revolución Socialista de Cuba: El Movimiento obrero cubano: documentos y artículos $^{7}$ (pela Editorial Pueblo y Educación, no qual o dirigente tem destaque) e Carlos Baliño: documentos y artículos $^{8}$ (compilação da obra completa editada pelo Departamento de Orientación Revolucionaria del Comitê Central del Partido Comunista de Cuba), tentaram suprir a lacuna em relação a este importante divulgador do marxismo na ilha. Mas ainda é pouco, em termos globais.

De qualquer forma, não se pode negar o pioneirismo do dirigente cubano (o "primeiro intelectual orgânico do proletariado”, nas palavras de Raúl Roa) (GÓMEZ GARCIA, 1985, p. 4), que, pelo menos desde 1889, já se considerava adepto do materialismo histórico, tendo como marco de sua adesão à doutrina o início de sua colaboração com o jornal La Tribuna del Trabajo, fundado por ele naquele ano. Vale lembrar que em 1905 Baliño publicaria o "folheto" Verdades socialistas, considerada "a primeira exposição desta magnitude que se escreve em Cuba sobre o socialismo marxista" (Instituto de Historia del Movimiento Comunista y de la Revolución Socialista de Cuba (org.), 1976, p. 260). Ou seja, mais de vinte anos antes dos Sete ensaios de interpretação da realidade peruana de Mariátegui. É verdade que no caso do tabaqueiro havanês, tratava-se de um texto curto, sem a mesma extensão ou sofisticação do trabalho do Amauta, que produziu um dos livros mais importantes do continente. Mas Gómez García irá insistir no fato de seu biografado ter sido o primeiro a iniciar na região a difusão sistemática das teorias do filósofo renano, além de se dedicar recorrentemente à questão do imperialismo e de organização política. Irá ressaltar, para isso, o fato de Cuba, segundo ela, "ser o primeiro país submetido à dominação neocolonial imperialista", o que levaria a classe operária cubana a ser sujeitada "antes que qualquer outra da América Latina, a uma violenta exploração”. Isso, aliado à maior organização e desenvolvimento do proletariado norte-americano, que influenciaria militantes cubanos vivendo nos Estados Unidos, ajudaria a disseminar o marxismo na ilha (GÓMEZ GARCÍA, 1985, p. 208).

\footnotetext{
${ }^{7}$ Cf. Instituto de Historia del Movimiento Comunista y la Revolución Socialista de Cuba. El movimiento obrero cubano: documentos y artículos. Havana: Editorial Pueblo y Educación, 1977.

${ }^{8} C f$. Instituto de Historia del Movimiento Comunista y de la Revolución Socialista de Cuba (org.). Carlos Baliño, documentos y articulos. Havana: Instituto de Historia del Movimiento Comunista y de la Revolución Socialista de Cuba/Departamento de Orientación Revolucionaria del Comité Central del Partido Comunista de Cuba, 1976.
}

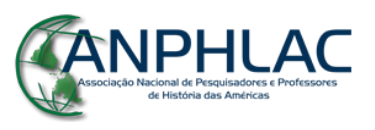

Revista Eletrônica da ANPHLAC, ISSN 1679-1061, №. 20, p. 126-140, Jan/Jun., 2016. http://revista.anphlac.org.br 
A trajetória de Baliño, que nasceu no emblemático ano de 1848 (caracterizado pelas revoluções na Europa e pela publicação do Manifesto comunista), une a luta anticolonialista e independentista com a defesa e difusão de um projeto socialista já no final do século XIX. Quando triunfou a revolução de Outubro, em 1917, ele seria um dos primeiros em Cuba a aderir a seus preceitos, apoiando os bolcheviques e a consolidação do regime soviético.

Não deixa de ser interessante notar que ele viveu e militou por mais de trinta anos nos Estados Unidos (de 1869 a 1902), tanto em Nova York e Nova Orleans (Louisiana), como também em Key West, Tampa e Jacksonville (na Flórida). Ou seja, toda sua formação política se realizou, efetivamente, no "Colosso do Norte" e foi lá que absorveu e desenvolveu seu ideário influenciado em grande medida pelo marxismo. Gómez García sugere uma aproximação aos elementos do Partido Socialista Operário, a agremiação liderada por Daniel De Leon, influente em alguns círculos radicais do proletariado local. ${ }^{9}$ Se isto de fato ocorreu, temos um caso singular de recepção do marxismo na América Latina a partir da vertente deleonista, o que é bastante factível se analisarmos mais detidamente a atuação e o pensamento do autor de "En marcha hacia la vida y la libertad" e diretor de Lucha de Clases, o primeiro periódico "marxista-leninista" de seu país.

Os Estados Unidos sempre estiveram entre suas preocupações. Sua denúncia contra racismo será explicitada num texto contundente contra a "abominável” e "sinistra sociedade secreta" $\mathrm{Ku}$ Klux Klan (BALIÑO (utilizando o pseudônimo P. Chero). Como siempre. Boletín del Torcedor, Havana, 31 de outubro de 1921, in Instituto de Historia del Movimiento Comunista y de la Revolución Socialista de Cuba (org.). , p. 155-158). Por outro lado, em "El nuevo negro

\footnotetext{
${ }^{9}$ Nascido em Curaçao, em 1852, Daniel De Leon, já adulto, mudou-se para Nova York, onde se tornou lecturer da Columbia University e, depois, o principal dirigente do SLP. Mais tarde, foi um dos fundadores da STLA e da IWW. Editor do jornal The People, traduziu $O 18$ de brumário e a Crítica do Programa de Gotha, de Marx, Socialism: From Utopia to Science, de Engels, e vários trabalhos de Karl Kautsky, August Bebel, Eugène Sue e Ferdinand Lassalle (apesar de fazer críticas a aspectos de seu pensamento). Foi, sem dúvida alguma, um dos principais disseminadores da literatura radical em inglês naquele país. Polemista, também produziu grande quantidade de artigos, editoriais e discursos. Ele "nacionalizou" o SLP e lutou para uma integração orgânica entre o trade unionismo e o socialismo. Para mais informações sobre Daniel De Leon, $c f$. L. Glen Seretan, Daniel De Leon, The Odyssey of an American Marxist (Cambridge, Harvard University Press, 1979); Stephen Coleman, Daniel De Leon (Manchester, Manchester University Press, 1990), Rudolph Schwab et al., Daniel De Leon, The Man and His Work, A Symposium (Nova York, National Executive Committee of the Socialist Labor Party, 1934); e David Herreshoff, The Origins of American Marxism (Nova York, Monad, 1973).
}

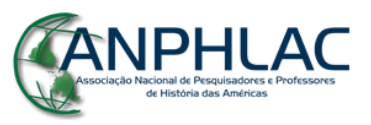


americano", mostrará a importância do orgulho dos afro-americanos e de sua luta contra o preconceito étnico (BALIÑO, El nuevo negro americano. Espartaco, revista ilustrada, Havana, Ano I, outubro de 1922. In Ibid, p. 180). Baliño foi membro da Nobre Ordem dos Cavaleiros do Trabalho, a organização sindical criada por Uriah Stephens na qual "se congregavam os trabalhadores sem distinção de nacionalidades, de sexos nem de cores" (IBID, p. 180), sendo o único delegado cubano entre os 800 presentes na Convenção de Richmond em 1886. Representou os Knights of Labor da Flórida. "Chegou o momento de se erguerem todos os que até agora andaram de joelhos", (IBID, p. 181), diria ele. Lembraria da importância da Rand School, em Nova York; de dois intelectuais negros que lá figuravam "brilhantemente", Chandler Owen e A. Phillip Randolph; e da revista mensal que editavam, The Messenger (1917-1928), publicação que tinha

a missão de levantar a grande massa de negros americanos da abjeta submissão, do servil rebaixamento em que até agora tem vivido. Incita os homens de sua raça a combater resolutamente os linchadores de negros... e ao mesmo tempo os incita... sobretudo, a engrossar a falange socialista para a redenção final de todos os oprimidos e humilhados. (BALIÑO, "El nuevo negro americano"in: Instituto de Historia del Movimiento Comunista y de la Revolución Socialista de Cuba (org.)., 1976, p. 183).

Anos antes (1894), em carta a Rafael Sierra, elogiaria o amigo jornalista por querer "publicar retratos e biografias dos homens de cor que mais se destacaram no ramo do saber" (BALIÑO, carta a Rafael Serra in: Instituto de Historia del Movimiento Comunista y de la Revolución Socialista de Cuba (org.)., 1976, p. 39). Discutiria a questão "racial” junto à operária:

Eu não creio que a escravidão tenha sido abolida, mas sim que tenha sofrido uma transformação. Em vez de somente escravidão doméstica para os negros, temos a escravidão industrial para brancos e negros. O escravo da plantação foi substituído pelo escravo da fábrica. E sou um abolicionista tão ardoroso para uma forma de escravidão como para a outra. As relações de patrões e operários são relações de amo e escravo, por mais que se disfarcem, às vezes, com respeitos e cortesias mútuas. (BALIÑO, carta a Rafael Serra in: Instituto de Historia del Movimiento Comunista y de la Revolución Socialista de Cuba (org.)., 1976, p. 39, 40).

Já em "El suicidio de los niños”, mostrará como crianças proletárias, "que trabalham longuíssimas jornadas por um mísero pagamento diário, insuficiente para alimentá-los

\section{RANPHLAC}


devidamente, no país mais rico do mundo, os Estados Unidos”, tiravam a própria vida, em desespero, por causa da superexploração de famílias inteiras (BALIÑO, "El suicidio de los niños", Juventud, Havana, maio de 1925. In ibid., p. 195-202). Um texto duro, impactante, contundente, que lembra bastante, em certos momentos, alguns artigos icônicos de Jack London.

No breve "Internacionalismo obrero frente al internacionalismo capitalista", por sua vez, atacará a opressão e os interesses de Washington em Cuba. E, como vários de sua época, acreditaria que a ideia de "revolução social" se espalhava nos Estados Unidos, com as consciências despertando entre os operários, que atacavam o "imperialismo capitalista", em seu protesto contra a ocupação das Filipinas, Haiti e Santo Domingo e contra sua ingerência nos assuntos dos povos da América Latina, estendendo suas mãos "por cima das fronteiras a seus irmãos de escravidão econômica" (BALIÑO, "Internacionalismo obrero frente al internacionalismo capitalista", Juventud, Havana, outubro de 1923. In ibid., p. 186). O internacionalismo proletário para ele, portanto, seria uma realidade. Traduziria em 1924, para o Juventud, "Los banqueros americanos apoderándose de la América Latina", opúsculo retirado do Daily Worker de Nova York (jornal publicado pelo Partido Comunista dos Estados Unidos), no qual se expunha explicitamente a penetração financeira dos Estados Unidos no continente. Um ataque claro às políticas de Wall Street e da Casa Branca (Los banqueros Americanos apoderándose de la América Latina. (traduzido por Carlos Baliño), Juventud, Havana, novembro de 1924. In ibid., p. 191-194).

Vários anos antes, em 1896, ele já havia vertido para o espanhol e preparado o prólogo de La nueva esclavitud, de H. Davis, lançado pelo Centro de Propaganda Obrera, em Tampa (Flórida), denunciando a ingerência norte-americana em Cuba (elaboraria uma nova apresentação para a segunda edição da mesma obra, 25 anos depois) (BALIÑO, Dos prólogos de Carlos Baliño al libro de H. Davis. In ibid., p. 41-44). O imperialismo, sem dúvida, seria um assunto de grande interesse para ele. Nesse sentido, o mais importante trabalho ligado ao tema foi provavelmente a tradução (por iniciativa própria), em 1921, de El imperio americano, livro de Scott Nearing, o qual também prefaciou.

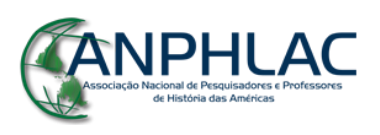

Revista Eletrônica da ANPHLAC, ISSN 1679-1061, №. 20, p. 126-140, Jan/Jun., 2016.

http://revista.anphlac.org.br 
O período em que esteve nos Estados Unidos, de fato, foi de intensa atividade política. Naquele país trabalhou na indústria do tabaco (foi, inclusive, dirigente do "Gremio de escojedores"), colaborou com diversas publicações locais (como La Tribuna del Trabajo, La Nueva República, El Mundo e El Proletario), participou da inauguração do Liceo Cubano de Key West, pronunciou discursos, presidiu o clube de emigrados revolucionários Leopoldo Turla, ajudou a fundar o município de Martí City em Ocala (Flórida), esteve em diversos atos públicos e proferiu várias conferências sobre o socialismo.

Vale recordar que era comum a presença de cubanos vivendo e trabalhando na "América". Lá estiveram personalidades políticas importantes, como Diego Vicente Tijera, Ramón Rivero, Julio Antonio Mella e José Martí, entre outros. Além de muitos trabalhadores, especialmente tabaqueiros, que por falta de emprego na ilha ou por perseguição das autoridades locais, seguiam em busca de uma ocupação na indústria de charutos do "Colosso do Norte".

A relação de Baliño com Martí deve ser ressaltada. Os dois se encontraram pela primeira vez em 1891, em Tampa, e a amizade foi instantânea. No ano seguinte, Baliño seria um dos signatários da ata de fundação do Partido Revolucionário Cubano, redigida pelo poeta, que convidou o colega a percorrer a península com ele, ambos discursando para o público da região. Como presidente do clube revolucionário Francisco Vicente Aguilera, ajudou a eleger Martí como delegado do PRC, esforçando-se para criar novos núcleos da agremiação (chegaria a ocupar a direção e, depois, a secretaria de seu Conselho, por algum tempo) ${ }^{10}$ (SERRA, 1985, p. 39). Foi lugar-tenente "não-militar" do general Rafael de Quesada em seus preparativos como expedicionário, sendo considerado, mais tarde, um "poderoso” auxiliar civil da revolução de 1895. Em novembro de 1897, ele assinaria um documento do PRC expressando, em nome dos tabaqueiros, seu incondicional apoio à causa da independência e seu repúdio ao governo "autonomista" sugerido pela Espanha (IBID, p. 47). A partir de janeiro de 1899, consternado com

\footnotetext{
${ }^{10}$ Em Tampa, Key West e outras localidades, foram criados mais de 150 clubes revolucionários dirigidos por seu partido. Cf. Mariana Serra. Carlos Baliño. Havana: Editorial Gente Nueva, 1985, p. 41.
}

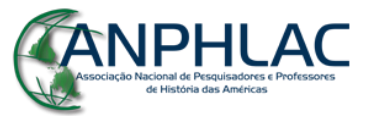

Revista Eletrônica da ANPHLAC, ISSN 1679-1061, №. 20, p. 126-140, Jan/Jun., 2016. http://revista.anphlac.org.br 
a intervenção militar dos Estados Unidos na ilha, rechaçaria o papel de Washington. Poucos anos depois, retornaria a seu país.

A influência martiana se fez evidente no ideário de Baliño, que percebeu ser mister, naquele momento, a prioridade da luta independentista, deixando para um segundo momento, a luta pela libertação social, vendo na constituição de um partido político a ferramenta fundamental para atingir tal objetivo. Logo em seguida, contudo, daria ênfase à pugna contra a ingerência econômica norte-americana em Cuba (GÓMEZ GARCIA, 1985, p. 114-115).

Após seu retorno a Havana, a militância ganharia uma nova dimensão em sua vida. Tentaria por em prática, desta vez, o arcabouço marxista nas organizações políticas que ajudaria a constituir. Quando voltou ao país, em 1902, Baliño tinha mais de 50 anos de idade; estava em plena maturidade. E seria somente a partir daí que atuaria dentro da ilha.

Com o mesmo entusiasmo da juventude, empenhar-se-ia incansavelmente em moldar os instrumentos de ação do proletariado local. Não poderia contar com Martí, que perdera a vida poucos anos antes na luta independentista, ainda que seu ideário certamente permanecesse arraigado nas concepções do tabaqueiro, que mesclaria a linha martiniana com o marxismo de linhagem deleonista. O PRC havia sido dissolvido, a penetração e dominação ianque se ampliavam e os problemas dos trabalhadores continuavam tão graves como antes. A experiência partidária e sindical de Baliño na Flórida, que mantinha relações muito próximas com Cuba, serviria como alicerce para sua nova empreitada.

Ao longo dos anos, construiria clubes de propaganda, editaria jornais e fundaria partidos operários. A primeira organização constituída por ele foi o Clube de Propaganda Socialista, em 18 de novembro de 1903, que tinha como objetivo estudar e divulgar o marxismo. Neste caso, a ideia não era a criação de um partido ou sindicato, mas o ensino mútuo dos princípios do "socialismo internacional", instruir-se por meio de gabinetes de leitura, conferências, meetings e excursões ao interior, além de manter correspondência com todos os organismos operários nacionais e estrangeiros para divulgar por toda a ilha seu "credo social".

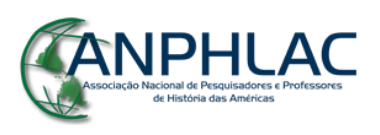

Revista Eletrônica da ANPHLAC, ISSN 1679-1061, №. 20, p. 126-140, Jan/Jun., 2016.

http://revista.anphlac.org.br 
O regulamento de fundação da agremiação, certificado pelo secretário José Francisco Hernández, continha doze artigos e indicava que esta era composta de uma Junta Diretiva, com um presidente, dois secretários, um contador e um tesoureiro. Para arcar com os gastos, os sócios deveriam pagar uma pequena cota mensal, que poderia diminuir ou aumentar segundo as necessidades do grupo. As coletas extraordinárias voluntárias também poderiam ser efetivadas, caso fosse necessário (Reglamento del Club de Propaganda Socialista de la Isla de Cuba. In Instituto de Historia del Movimiento Comunista y de la Revolución Socialista de Cuba (org.). , 1976, p. 219-221). Seus membros defendiam como premissa fundamental o estabelecimento de empresas e indústrias socializadas, ou seja, que fossem propriedade coletiva do povo ou administradas pelo Estado, província ou município, segundo seu tamanho e extensão, com a tendência à diminuição gradual da jornada de trabalho e ao aumento da retribuição do trabalhador (Acta de fundación del Club de Propaganda Socialista de la Isla de Cuba. In Ibid., p. 215-218). Todos os homens "amantes do bem", quaisquer que fossem as posições que ocupassem, estavam convidados a participar desta "obra de amor e de progresso". Segundo a declaração, "não é missão dos socialistas eliminar a classe média, já que a estão eliminando os trustes por meio das forças econômicas que são irresistíveis" (IBID, p. 217). O Clube tinha como intenção, portanto, mostrar a identidade de interesse entre os proletários rurais e os trabalhadores urbanos (intelectuais, comerciantes e funcionários da "burocracia"). A fundação do Clube seria fundamental para o desenvolvimento do marxismo dentro de Cuba.

Já em 1904, Baliño se corresponderia com lideranças do recém-fundado Partido Obrero, aproximando-se deste e começando um trabalho ideológico que influenciaria seus estatutos, inclusive, colaborando com seu órgão La Voz Obrera. No ano seguinte, ele escreveria "Bases fundamentales", que seriam incorporadas por seu Comitê Organizador, em 20 de setembro de 1905. O documento defendia a tomada do poder político pelos operários, a conversão da propriedade individual ou corporativa em coletiva ou comum e a organização da sociedade a partir de uma federação econômica, garantindo a todos os seus membros o produto integral de seu trabalho, o usufruto dos instrumentos de labor e o ensino geral científico para todas as profissões, a homens e

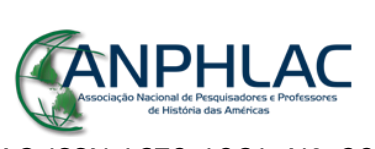


mulheres. Sua finalidade: a completa emancipação da classe proletária, com a abolição das classes sociais (Bases fundamentales del Partido Obrero. In ibid., p. 223-224).

Naquele mesmo ano, o Clube de Propaganda Socialista e o Partido Obrero iriam se fundir, dando origem ao Partido Obrero Socialista (vale notar a semelhança do nome com o da sigla de Daniel De Leon), do qual Baliño se tornaria membro da direção. O processo de aglutinação das organizações políticas de esquerda se aceleraria, e no ano seguinte, o POS se unificaria com a Agrupación Socialista Internacional (integrada por imigrantes espanhóis), formando a partir daí o Partido Socialista de Cuba. Baliño faria parte de seu Comitê Central.

Em $1^{\circ}$ de dezembro de 1906, a agremiação lançaria seu manifesto: aquele deveria ser "um partido organizado pelos trabalhadores e para os trabalhadores", mesmo não excluindo os "homens de inteligência e de coração das classes mais favorecidas que venham às nossas fileiras lutar pela justiça social" (Manifiesto del Partido Socialista de Cuba. In ibid., p. 227-232). Defendia um programa de transição, que permitisse melhorar a vida dos obreiros e lutar pela consecução do ideal definitivo, a revolução, que poderia ser atingida de forma violenta ou pacífica. Neste último caso, por meio de partidos classistas, nos países onde o sufrágio popular permitisse fazer valer a vontade da maioria da população.

A revolução de Outubro iria influenciar toda uma geração. E Baliño se destacaria como um de seus primeiros apoiadores em Cuba. É possível dizer que ele foi a ponte entre os primórdios do marxismo cubano e a linhagem comunista e cominterniana. De um lado, assimilaria o marxismo norte-americano, deleonista, num período anterior aos eventos da Rússia, sem passar pela influência de Lênin e dos bolcheviques. De outro, seria dos primeiros a perceber a importância do novo momento histórico, incorporando a obra e as ideias leninistas a seu arcabouço teórico e se envolvendo diretamente na construção de um partido que deveria se vincular à IC.

É certo que ele conhecia o Partido Operário Social Democrata Russo havia algum tempo, e elogiara a luta pela revolução socialista naquele país já em 1906 no artigo "La revolución rusa" (BALIÑO, La revolución rusa. In ibid., p. 133-135) (atribuído a ele), publicado em La Voz Obrera

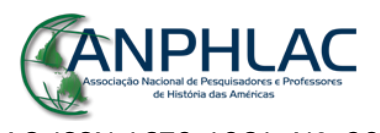

Revista Eletrônica da ANPHLAC, ISSN 1679-1061, №. 20, p. 126-140, Jan/Jun., 2016.

http://revista.anphlac.org.br 
de Havana. Mas mesmo em abril de 1917, em seu "En marcha hacia la vida y la libertad", não fará nenhuma menção ao autor de Imperialismo, fase superior do capitalismo, o que é algo bastante compreensível. ${ }^{11}$ Vale recordar que, antes daquele ano, na prática, poucos socialistas na América Latina conheciam o trabalho de Lênin. Na primeira metade dos 1920, contudo, em tributo à Rússia soviética, preparará o editorial "7 de noviembre" (BALIÑO, 7 de noviembre. In ibid., p. 173) para Espartaco número 2, e a homenagem póstuma "Lenin” (BALIÑO, Lenin. In ibid., p. 189, 190), publicada em Lucha de Clases em 30 de maio de 1924. Em termos gerais, um material escasso.

Mais importante, contudo, não foram os textos sobre a revolução russa, mas seu trabalho como idealizador, organizador e construtor do partido comunista de seu país. Em julho de 1922, a Agrupação Socialista de Havana havia decidido aderir ao Comintern; no mês seguinte, consequentemente, Baliño assinaria a "Declaração de princípios" com o dirigente operário José Villasuso, tornando-se na mesma época o diretor da revista Espartaco. Nos dois anos posteriores, seu trabalho organizacional o levará a apoiar a constituição de outros organismos socialistas dentro da ilha. Será um colaborador da revista Juventud, criada pelo jovem Julio Antonio Mella, assim como encabeçará mais um projeto editorial, Lucha de Clases (mais tarde, órgão do PCC). A fundação da seção cubana da Liga Anti-imperialista e do Partido Comunista Cubano, ambos em 1925, junto com Mella, será o coroamento de sua trajetória.

Tratava-se da confluência de duas gerações distintas, porém consoantes. Baliño conheceu Mella aos 75 anos, nas oficinas de El Ideal (onde eram publicados os jornais Justicia e Boletín del Torcedor, e a revista Juventud), em 1923, local onde, segundo a biógrafa Mariana Serra, o idoso sindicalista trabalhava como corretor de provas e tradutor (SERRA, 1985, p. 76). Os laços iriam se estreitar até o Congresso de fundação do Partido Comunista de Cuba, um par de anos depois, a partir de uma reunião convocada pela Agrupação Comunista de Havana, que juntou congêneres de outras cidades, como Guanabacoa, Regla, Manzanillo, Media Luna, Guantánamo e San Antonio de los Baños. Na ocasião, enquanto Baliño contava 77 anos de idade e tinha origem no sindicalismo, Mella era um rapaz de 22 anos que transitava no ambiente universitário, dentro do

\footnotetext{
${ }^{11}$ Cf. Boris Koval. La gran revolución de Octubre y América Latina. Moscou: Editorial Progreso, 1978.
}

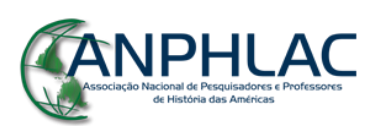

Revista Eletrônica da ANPHLAC, ISSN 1679-1061, №. 20, p. 126-140, Jan/Jun., 2016.

http://revista.anphlac.org.br 
movimento estudantil. Ambos seriam eleitos membros do Comitê Central na ocasião. A dupla, contudo, possuía vários traços similares: o anti-imperialismo, o nacionalismo, a admiração por José Martí, uma leitura similar de Lênin, a defesa pela luta comum reunindo estudantes, operários e camponeses e o apoio incondicional à União Soviética. ${ }^{12} \mathrm{Se}$, por um lado, Baliño conviveu com o poeta e mártir cubano, Mella seria o responsável por tentar resgatar e reelaborar seu pensamento para as novas gerações.

A fundação do PCC foi um momento importante da trajetória do tabaqueiro, mas representou também seu último suspiro político. Afinal, no ano de 1926 chegaria ao fim a vida do dirigente, então com 78 anos de idade, na capital do país, num momento em que a repressão machadiana recrudescia. De qualquer forma, este que foi chamado por José Martí de "gallardo proletario", deve ser recordado com destaque entre os pioneiros do marxismo na América Latina. Um estudo mais sistemático e aprofundado das ideias de Baliño por pesquisadores latinoamericanos (e, por conseguinte, brasileiros) é uma necessidade. Só assim, será possível dar prosseguimento a novas e originais investigações sobre outros aspectos do marxismo em nosso continente.

\section{Referências Bibliográficas}

ACTA DE FUNDACION DEL CLUB DE PROPANGA SOCIALISTA DE LA ISLA DE CUBA, in INSTITUTO DE HISTORIA DEL MOVIMIENTO COMUNISTA Y DE LA REVOLUCION SOCIALISTA DE CUBA (org.). Carlos Baliño: documentos y articulos. Havana: Instituto de Historia del Movimiento Comunista y de la Revolución Socialista de Cuba/Departamento de Orientación Revolucionaria del Comité Central del Partido Comunista de Cuba, 1976.

AGUILAR, Luís E. (org.). Marxism in Latin America. Nova Iorque: Alfred A. Knopf, 1968.

\footnotetext{
${ }^{12}$ Para mais detalhes sobre as ideias de Julio Antonio Mella, $c f$. Instituto de Historia del Movimiento Comunista y la Revolución Socialista de Cuba. J. A. Mella: documentos y artículos. Havana: Editorial de Ciencias Sociales/Instituto Cubano del Libro, 1975.
}

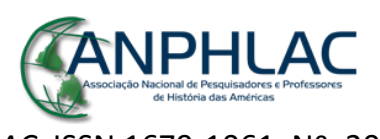

Revista Eletrônica da ANPHLAC, ISSN 1679-1061, №. 20, p. 126-140, Jan/Jun., 2016.

http://revista.anphlac.org.br 
BALIÑO, Carlos, Carta de Carlos Baliño a Rafael Serra, Ocala, Flórida, 6 de outubro de 1894, in INSTITUTO DE HISTORIA DEL MOVIMIENTO COMUNISTA Y DE LA REVOLUCION SOCIALISTA DE CUBA (org.). Carlos Baliño: documentos y articulos. Havana: Instituto de Historia del Movimiento Comunista y de la Revolución Socialista de Cuba/Departamento de Orientación Revolucionaria del Comité Central del Partido Comunista de Cuba, 1976.

. (utilizando o pseudônimo P. Chero). Como siempre, in INSTITUTO DE HISTORIA DEL MOVIMIENTO COMUNISTA Y DE LA REVOLUCION SOCIALISTA DE CUBA (org.). Carlos Baliño: documentos y articulos. Havana: Instituto de Historia del Movimiento Comunista y de la Revolución Socialista de Cuba/Departamento de Orientación Revolucionaria del Comité Central del Partido Comunista de Cuba, 1976.

. Dos prólogos de Carlos Baliño al libro de H. Davis. In INSTITUTO DE HISTORIA DEL MOVIMIENTO COMUNISTA Y DE LA REVOLUCION SOCIALISTA DE CUBA (org.). Carlos Baliño: documentos y articulos. Havana: Instituto de Historia del Movimiento Comunista y de la Revolución Socialista de Cuba/Departamento de Orientación Revolucionaria del Comité Central del Partido Comunista de Cuba, 1976.

El nuevo negro americano. In INSTITUTO DE HISTORIA DEL MOVIMIENTO COMUNISTA Y DE LA REVOLUCION SOCIALISTA DE CUBA (org.). Carlos Baliño: documentos y articulos. Havana: Instituto de Historia del Movimiento Comunista y de la Revolución Socialista de Cuba/Departamento de Orientación Revolucionaria del Comité Central del Partido Comunista de Cuba, 1976.

. El suicidio de los niños. In INSTITUTO DE HISTORIA DEL MOVIMIENTO COMUNISTA Y DE LA REVOLUCION SOCIALISTA DE CUBA (org.). Carlos Baliño: documentos y articulos. Havana: Instituto de Historia del Movimiento Comunista y de la Revolución Socialista de Cuba/Departamento de Orientación Revolucionaria del Comité Central del Partido Comunista de Cuba, 1976.

. Internacionalismo obrero frente al internacionalismo capitalista. In INSTITUTO DE HISTORIA DEL MOVIMIENTO COMUNISTA Y DE LA REVOLUCION SOCIALISTA DE CUBA (org.). Carlos Baliño: documentos y articulos. Havana: Instituto de Historia del Movimiento Comunista y de la Revolución Socialista de Cuba/Departamento de Orientación Revolucionaria del Comité Central del Partido Comunista de Cuba, 1976.

. La revolución rusa. In INSTITUTO DE HISTORIA DEL MOVIMIENTO COMUNISTA Y DE LA REVOLUCION SOCIALISTA DE CUBA (org.). Carlos Baliño: documentos y articulos. Havana: Instituto de Historia del Movimiento Comunista y de la Revolución Socialista de Cuba/Departamento de Orientación Revolucionaria del Comité Central del Partido Comunista de Cuba, 1976.

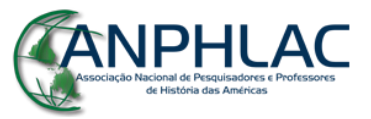


Lenin. In INSTITUTO DE HISTORIA DEL MOVIMIENTO COMUNISTA Y DE LA REVOLUCION SOCIALISTA DE CUBA (org.). Carlos Baliño: documentos y articulos. Havana: Instituto de Historia del Movimiento Comunista y de la Revolución Socialista de Cuba/Departamento de Orientación Revolucionaria del Comité Central del Partido Comunista de Cuba, 1976.

. 7 de noviembre. In INSTITUTO DE HISTORIA DEL MOVIMIENTO COMUNISTA Y DE LA REVOLUCION SOCIALISTA DE CUBA (org.). Carlos Baliño: documentos y articulos. Havana: Instituto de Historia del Movimiento Comunista y de la Revolución Socialista de Cuba/Departamento de Orientación Revolucionaria del Comité Central del Partido Comunista de Cuba, 1976.

BASES FUNDAMENTALES DEL PARTIDO OBRERO. In INSTITUTO DE HISTORIA DEL MOVIMIENTO COMUNISTA Y DE LA REVOLUCION SOCIALISTA DE CUBA (org.). Carlos Baliño: documentos y articulos. Havana: Instituto de Historia del Movimiento Comunista y de la Revolución Socialista de Cuba/Departamento de Orientación Revolucionaria del Comité Central del Partido Comunista de Cuba, 1976.

COLEMAN, Stephen. Daniel De Leon. Manchester: Manchester University Press, 1990.

GÓMEZ GARCÍA, Carmen. Carlos Baliño, primer pensador marxista cubano. Havana: Editorial de Ciencias Sociales, 1985.

HERRESHOFF, David. The Origins of American Marxism. Nova York: Monad, 1973.

INSTITUTO DE HISTORIA DEL MOVIMIENTO COMUNISTA Y DE LA REVOLUCION SOCIALISTA DE CUBA (org.). Carlos Baliño: documentos y articulos. Havana: Instituto de Historia del Movimiento Comunista y de la Revolución Socialista de Cuba/Departamento de Orientación Revolucionaria del Comité Central del Partido Comunista de Cuba, 1976.

(org.). El movimiento obrero cubano: documentos y artículos. Havana, Editorial Pueblo y Educación, 1977.

J. A. Mella: documentos y artículos. Havana: Editorial de Ciencias Sociales/Instituto Cubano del Libro, 1975.

JEIFETS, Lazar; JEIFETS, Víctor; HUBER, Peter (orgs.). América Latina en la Internacional Comunista, 1919-1943. Santiago do Chile: Ariadna Ediciones, 2015.

KOHAN, Néstor. En la selva. Buenos Aires: Editorial Yulca/Ediciones La Llamarada/Amauta Insurgente Ediciones, 2013.

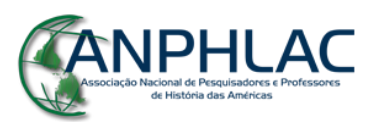

Revista Eletrônica da ANPHLAC, ISSN 1679-1061, №. 20, p. 126-140, Jan/Jun., 2016.

http://revista.anphlac.org.br 
KOVAL, Boris. La gran revolución de Octubre y América Latina. Moscou: Editorial Progreso, 1978.

LISS, Sheldon B. Marxist Thought in Latin America. University of California Press, 1984.

LOS BANQUEROS AMERICANOS APODERANDOSE DE LA AMERICA LATINA (traduzido por Carlos Baliño). In INSTITUTO DE HISTORIA DEL MOVIMIENTO COMUNISTA Y DE LA REVOLUCION SOCIALISTA DE CUBA (org.). Carlos Baliño: documentos y articulos. Havana: Instituto de Historia del Movimiento Comunista y de la Revolución Socialista de Cuba/Departamento de Orientación Revolucionaria del Comité Central del Partido Comunista de Cuba, 1976.

LÖWY, Michael (org.). O marxismo na América Latina: uma antologia de 1909 aos dias atuais. São Paulo: Editora Fundação Perseu Abramo, 2012.

MANIFIESTO DEL PARTIDO SOCIALISTA DE CUBA. In INSTITUTO DE HISTORIA DEL MOVIMIENTO COMUNISTA Y DE LA REVOLUCION SOCIALISTA DE CUBA (org.). Carlos Baliño: documentos y articulos. Havana: Instituto de Historia del Movimiento Comunista y de la Revolución Socialista de Cuba/Departamento de Orientación Revolucionaria del Comité Central del Partido Comunista de Cuba, 1976.

REGLAMENTO DEL CLUB DE PROPAGANDA SOCIALISTA DE LA ISLA DE CUBA. In Instituto de Historia del Movimiento Comunista y de la Revolución Socialista de Cuba (org.). Carlos Baliño: documentos y articulos. Havana: Instituto de Historia del Movimiento Comunista y de la Revolución Socialista de Cuba/Departamento de Orientación Revolucionaria del Comité Central del Partido Comunista de Cuba, 1976.

ROCA, Blas, Prólogo de Blas Roca al folleto Verdades del Socialismo. In Instituto de Historia del Movimiento Comunista y de la Revolución Socialista de Cuba (org.). Carlos Baliño: documentos y articulos. Havana: Instituto de Historia del Movimiento Comunista y de la Revolución Socialista de Cuba/Departamento de Orientación Revolucionaria del Comité Central del Partido Comunista de Cuba, 1976.

SCHWAB, Rudolph et al. Daniel De Leon, The Man and His Work, A Symposium. Nova York: National Executive Committee of the Socialist Labor Party, 1934.

SERETAN, L. Glen. Daniel De Leon, The Odyssey of an American Marxist. Cambridge: Harvard University Press, 1979.

SERRA, Mariana. Carlos Baliño. Havana: Editorial Gente Nueva, 1985.

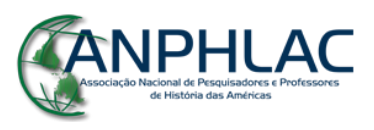

Revista Eletrônica da ANPHLAC, ISSN 1679-1061, №. 20, p. 126-140, Jan/Jun., 2016.

http://revista.anphlac.org.br 